\title{
Assessment of the temperature cut-off point by a commercial intravaginal device to predict parturition in Piedmontese beef cows
}

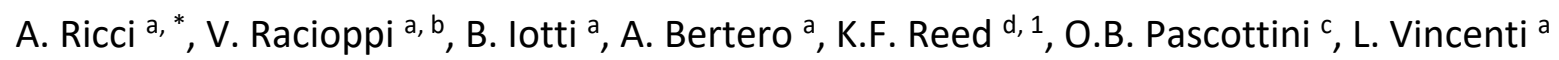

a Dip. di Scienze Veterinarie, Universita degli Studi di Torino, 10095, Grugliasco, Italy

b Practitioner, Torino, Italy

c Population Medicine, Ontario Veterinary College, University of Guelph, Ont N1G 2W1, Canada

d USDA-Agricultural Research Service, U. S. Dairy Forage Research Center, Madison, WI 53706,

United States

\begin{abstract}
Dystocic parturitions have an adverse impact on animal productivity and therefore the profitability of the farm. In this regard, accurate prediction of calving is essential since it allows for efficient and prompt assistance of the dam and the calf. Numerous approaches to predict parturition have been studied, among these, measurement of intravaginal temperature (IVT) is the most effective method at the field level. Thus, objectives of this experiment were, 1) to find an IVT cut-off to predict calving within $24 \mathrm{~h}$, and 2) to clarify the use of IVT as an automated method of calving detection in housed beef cows. A com- mercial intravaginal electronic device (Medria Vel'Phone ${ }^{\circledR}$ ) with a sensor that measures the IVT every $12 \mathrm{~h}$ was used. Piedmontese cows ( $\mathrm{1} / \mathrm{4} 211 ; 27$ primiparous and 184 multiparous) were included in this study. One-way analysis of variance was used to assess the temperature differences at $0,12,24,36,48$ and $60 \mathrm{~h}$ before parturition. Receiving operator characteristic curves were built to determine the tem- perature cut-off which predicts calving within $24 \mathrm{~h}$ with the highest summation of sensitivity (Se) and specificity (Sp). Binomial logistic regression models were computed to identify factors that may affect the IVT before calving. Mean gestation length was $291.5 \pm 13.7 \mathrm{~d}$ (primiparous, $292 \pm 14.1 \mathrm{~d}$; multiparous, $289 \pm 9.2 \mathrm{~d})$. A decrease $(P<0.001)$ in the average IVT was found from $60 \mathrm{~h}$ before calving until the expulsion of the IVT device. A significant $(P<0.05)$ reduction in the IVT was noticeable from $24 \mathrm{~h}$ before until parturition. The IVT drop to predict parturition $24 \mathrm{~h}$ before calving was $0.21^{\circ} \mathrm{C}$ (area under the curve [AUC] 1/4 0.72; Se 1/4 66\%, Sp 1/4 76\%). Furthermore, the IVT cut-off value to predict parturition within $24 \mathrm{~h}$ was $38.2^{\circ} \mathrm{C}$ (AUC 1/4 0.89; Se 1/4 86\%, Sp 1/4 91\%). None of the evaluated fixed effects (parity, dystocia, season or length of gestation) affected ( $P>0.05$ ) the IVT variation from $60 \mathrm{~h}$ before and up to calving. To conclude, the IVT average seems to be a better parameter than the drop in temperature to predict parturition within $24 \mathrm{~h}$. In this regard, a cut-off of $38.2^{\circ} \mathrm{C}$ showed a high Se and Sp for predicting calving. This study demonstrates the usefulness of a commercially available device to predict calving to improve management in stabled beef farms.
\end{abstract}

\section{Introduction}

Parturition is a complex physiological event characterized by distinct physical and hormonal changes, observable up to $72 \mathrm{~h}$ before parturition. Both dystocia and stillbirth have a significant impact on animal productivity and the profitability of the farm; often requiring a skilled assistant and immediate intervention at the moment of delivery [1]. Moreover, dystocia has an adverse effect on future reproductive performance and cattle welfare with increased incidences of retained placenta (RP), uterine infections, and involuntary culling [2]. Patterson et al. [3] described dystocia as the primary cause of calf mortality in the first $96 \mathrm{~h}$ of life. Human assistance at parturition is reported to occur only between 11 and $51 \%$ of parturitions in beef and dairy cattle [4e7]. When prompt and efficient assistance was achieved, a significant decrease in calf mortality, 
(RP), and postpartum infections were reported [8]. Therefore, accurate calving prediction is a determining factor to support animal welfare and herd profitability [9] and accurate calving management is crucial to reduce the adverse effects of dystocia for both the cow and the calf [12]. However, the broad variability in gestation length and the unclear identification of the beginning of parturition affect the possibility of prompt calving assistance [10,11].

Numerous methods to predict parturition have been presented in literature over the years. Some authors propose methods based on the measurement of external clinical signs of the preparatory stage of parturition such as pelvic relaxation, vaginal secretion and udder hyperplasia [13]. Other authors focused on measurement of the hormonal concentration of progesterone $[12,14]$ or estrone sulfate/17 $\beta$ estradiol in blood [15]. Ultrasound monitoring [16] and electrolyte concentrations in mammary gland secretions [11] have also been used as complementary methods to predict parturition. With advancements in image recognition technology, the use of continuous video-recording has also been investigated to monitor the onset of parturition [17]. The use of automated mechanical and electronic equipment is being implemented in all aspects of bovine livestock production including feeding, rumination, estrus detection and calving prediction [18e20]. Many new devices to predict parturition are now available on the market: accelerometers to detect tail raising and behavioral changes; abdominal belts to measure uterine contractions; intravaginal thermometers to evaluate temperature changes; and devices fixed in the vagina or at the vulvar lips to detect calf expulsion [9].

Cattle show a decrease in body temperature (Tb) before calving [21e26]. The Tb in beef cattle decreases from 48 to $8 \mathrm{~h}$ before calving and is not affected by the environmental temperature [27]. Lammoglia et al. [27] suggested that the decrease in maternal Tb (eg. vaginal temperature) before parturition is the consequence of the increased placental blood flow in the immediate precalving period. This increased blood flow causes a raise in the foetal temperature, which may mitigate heat loss by the neonatal calf in its new life ex utero. Interestingly, there is significant diurnal variation in the rectal and vaginal temperature of up to $0.5^{\circ} \mathrm{C}$, which is lower in the morning (0.2$0.3^{\circ} \mathrm{C}$ ) and higher in the late afternoon $\left(0.4-0.5^{\circ} \mathrm{C}\right)$, showing the importance of at least two repeated measurements per day $[25,28]$. Recently, the use of repeated Tb measurements (either rectal or intravaginal) has become one of the most used tools of telemetry in livestock production due to its easy assessment at the field level [28]. Variations in Tb has been used to predict the time of calving with different results $[25,30,31]$. Furthermore, there are no publications about the possibility of using a particular temperature cut-off to predict parturition.

"Double muscling" is a heritable condition present in the Piedmontese cattle, that results in muscular hypertrophy and hyperplasia [32]. The condition contributes to a low-fat and tender meat that has made the breed well known and spread all over the world, as confirmed by the National Association of Piedmontese Cattle Breeders (A.N.A.B.O.R.A.P.I.). Unfortunately, Piedmontese cows and in general double-muscle breeds are more susceptible to difficulties at parturition [1,33]. Due to the increased trauma associated with parturition in double muscle beef cattle, there is an increased need for accurate detection of the onset of parturition in order to provide assistance during labor. Thus, the primary objective of this experiment was to establish an intravaginal temperature (IVT) cut-off to predict calving in Piedmontese cows. Moreover, we aimed to clarify the utility of using an IVT as an automated method of calving detection in livestock farming to assist parturition in the case of dystocia.

\section{Materials and methods}

A total of 248 (219 multiparous and 29 primiparous) healthy pregnant Piedmontese cows from four small-to-medium size herds (30-200 cows) located in the Piedmont region of Italy were enrolled in the present study from November 2013 to April 2015. All cows were submitted to Al 
after heat detection and checked for pregnancy at 32e35 days post-Al by a skilled veterinarian via ultrasound examination. All animals were housed in free stall barns throughout the entire year. Adequate ad libitum feed was provided (hay, bent grass, and corn flour and soya) enriched with vitamins ( $A$ and $E$ ) and mineral supplementation ( $\mathrm{Ca}, \mathrm{P}$ and $\mathrm{Mg}$ ). All herds were officially free of IBR, tuberculosis, brucellosis and enzootic bovine leucosis, and vaccinated against BVD and pneumonia.

The intravaginal electronic device (Medria Vel'Phone ${ }^{\circledR}$, Chateaubourg, France) is an on-farm tool designed to predict (and alarm) calving by the IVT variation and expulsion of the device just before parturition. The device consists of a rigid tube with a plastic mandrel in which a temperature detector (TDetector) is inserted, covered with a plastic shell with ridges (Fig. 1a). The tool is produced in two different sizes: large (for cows) and small (for heifers) (Fig. 1b). Briefly, after cleansing the device and the perineal area of the cow with a povidone-iodine solution (Betadine ${ }^{\circledR}$ ), the tubular support was gently inserted in the vulva and the TDetector was deposited deep into the vagina (Fig. 2). As indicated by the manufacturer, the TDetector should be introduced $7 \mathrm{~d}$ before expected parturition, considered to be between 278 and 283 days in pregnancy depending on breed, age, weight of the calf, milk yield, and season of parturition [34,35]. Once the TDetector is in the cranial vagina, its thermometric sensor generates a radio wave signal which is transmitted to a receiver (Fig. 3) that analyzes the data and sends a text message via Global System for Mobile (GSM) communication technology to the herd staff mobile phone; providing an alert of the prediction (IVT variation) or the imminent beginning of calving (device expulsion, EXP). Vel'phone monitors the IVT every $12 \mathrm{~h}$ (8:00 and 20:00), starting from the day of the device insertion until delivery. A brief description of the Vel'Phone function process is described in Fig. 4.

Although the literature has discordant definitions of dystocia $[33,36]$ for this study we categorized parturitions into three groups:

- eutocic: the autonomous and spontaneous calving. There is not an active intervention from the staff members.

Dystocic parturitions were separated into two categories:

- assisted: calving in need of assistance with a weak or a strong traction from the farmer, or requires intervention from a veterinarian.

- caesarean: parturition that requires a caesarean section.

\subsection{Statistical analysis}

The day of TDetector insertion, IVT for each day (2 times per day), and date and temperature at EXP were exported from the Medria Vel'phone ${ }^{\circledR}$ to a Microsoft Excel (Microsoft Corporation, Redmond, WA) spreadsheet file. All data were statistically analyzed via R version 3.3.0 (R Core Team, Vienna, Austria). Descriptive statistics (mean, median, quartiles and standard deviation) were calculated using the summary functions of $\mathrm{R}$ software (stats package). Verification of the assumption of normality was evaluated using Shapiro-Wilk's test and F-Folded or Levene's variance uniformity for all continuous data (stats package). The statistical significance level was set at $\mathrm{P}<0.05$.

A scatter plot with a smooth curve fitted by Loess (princurve package) of all IVT measurements for each cow by day was created based on measurements recorded from $60 \mathrm{~h}$ before parturition until EXP. One-way ANOVA (car package) was used to assess temperature differences at $0,12,24,36$, 48 and $60 \mathrm{~h}$ before parturition (parturition 1/4 EXP). Next, the optimal IVT cut-off point to predict calving (within $24 \mathrm{~h}$ ), with the greatest summation of sensitivity (Se) and specificity (Sp) and its respective positive predictive value (PPV) and negative predictive value (NPV), was calculated. For this, two receiver operator characteristics (ROC) curves (pROC package) and the area under the curve (cvAUC package) were constructed. For the first ROC curve, the average IVT were sorted into 
three groups, $0 \mathrm{e} 12,24 \mathrm{e} 36$ and $48 \mathrm{e} 60 \mathrm{~h}$ before parturition, and used as the predictor variable. The classifier (calved/not calved) was set as the calving result in the average IVT at 0e12 $\mathrm{h}$ (calved), $24 \mathrm{e} 36 \mathrm{~h}$ (not calved) and $48 \mathrm{e} 60 \mathrm{~h}$ (not calved) before parturition. A second ROC curve was created in order to find the cut-off point which indicates the IVT drop difference with the greatest sensitivity and specificity. For this ROC curve, the average IVT difference between 0 and $12 \mathrm{~h}$ with $24 \mathrm{e} 36 \mathrm{~h}$ before calving (predictor $1 / 4$ calved) and the IVT difference between 24-36 and $48 \mathrm{e} 60 \mathrm{~h}$ before calving (predictor $1 / 4$ not calved) was used as the classifier.

After establishing the IVT cut-off point, factors associated with the drop in the IVT before parturition were investigated. For this, binomial mixed effect models (package Ime4, function elmer) were constructed. The average IVT grouped at 0-12, 24-36 and 48-60 h before parturition were dichotomised as: below the cut-off point as a positive predictor for calving, and above the cut-off point as a negative predictor for calving. The fixed effects tested were ease of calving (eutocia, traction, caesarean), lactation number (primiparous, multiparous), gestation length (continuous variable), and season of calving (winter, spring, summer, fall). Moreover, the time (hours before the expulsion of the device) where the IVT before calving was measured was also included as fixed effect (IVT grouped at 0-12, 24-36 and 48-60 h before calving). All effects with Pvalues $<0.2$ (univariate) and their interactions were included in the final model, which was computed by backward stepwise elimination. Due to its better fit in the model (lowest Akaike and Bayesian information values), cow nested within farm was used as random effect. Results of the mixed effect models are expressed as odds ratio (OR) with their respective confidence intervals (Cl).

\section{Results}

Initially, 248 Piedmontese cows were included in the study. Thirty-seven cows were excluded due to unavailability of data, or because the device remained in the vagina for less than three days before its expulsion. Therefore, for the final data analysis, a total of 211 cows were included (27 primiparous and 184 multiparous). Mean gestation length was $291.5 \pm 13.7$. (primiparous, $292 \pm$ 14.1 days and multiparous, $289 \pm 9.2$, days). The TDetector was kept in the vagina an average of $8.5 \pm 6 \mathrm{~d}$. A total of $52.6 \%$ (111/211) of the subjects showed dystocia (assisted or caesarean); primiparous cows showed a higher tendency for dystocic calvings in comparison to multiparous cows $(70.3 \%(19 / 27)$ vs $50.0 \%(92 / 184), P=0.06)$. Although no statistical significance was found, primiparous cows had more caesarians and assisted deliveries in comparison with multiparous (25.6\% vs $23.9 \%, \mathrm{P}>0.05)$.

The average IVT trend from $60 \mathrm{~h}$ before parturition until EXP, is shown by the Loess curve (Fig. 5). ANOVA was applied to compare the average IVT between different time periods, from 0 to $60 \mathrm{~h}$ before calving (Table 1). A significant decrease in the IVT was noticeable from $24 \mathrm{~h}$ before until EXP. The mean IVT was grouped at 0-12, 24-36 and 48-60 $\mathrm{h}$ before parturition (Table 2), and a significant drop was recorded from $24-36 \mathrm{~h}$ to $0-12 \mathrm{~h}\left(38.48 \pm 0.25\right.$ vs $\left.38.12 \pm 0.25^{\circ} \mathrm{C}\right)$. The ROC and AUC outputs used for defining the cut-off of IVT to predict parturition $24 \mathrm{~h}$ before the calving event are illustrated in Fig. 6. Based on this analysis, the IVT cut-off to predict calving was set at $38.2^{\circ} \mathrm{C}(\mathrm{Se}=86 \%, \mathrm{Sp}=91 \%$; PPV $=80 \%, \mathrm{NPV}=88 \%$; AUC $=0.89$ ) (Table 3). When a variation of IVT was considered as the value to predict parturition, the cut-off was $-0.21^{\circ} \mathrm{C}$ (indicating a drop in IVT) with Se $=66 \%, \mathrm{Sp}=76 \%$, PPV $=67 \%$, and NPV $=69 \%$ (AUC $=0.72$ ) (Table 3). Results of the binomial mixed effect models revealing the factors associated with a variation in the IVT before calving are illustrated in Table 4 and indicate that parity, type of calving, season, and length of gestation did not influence the change in intravaginal temperature before parturition.

\section{Discussion}


Although different IVT devices have been used in research for years, very few are present in the market for its use on commercial farms [9] and most of them lack evidence about the degree of effectiveness to predict parturition. This study is one of the first to use an intravaginal sensor system available on the market to evaluate the accuracy of IVT as calving predictor on commercial farms. In this system, IVT measurements were immediately and wirelessly recorded with a smartphone, allowing for better control and notification at the time of delivery than retrospective data collection (useful for research but not for commercial use). The TDetector stayed in the vagina for more than one week (in some cases up to $20 \mathrm{~d}$ ), and did not cause any secondary effects or lesions in the cow (data not shown). Eventually, a temporary, mild vaginitis was observed. Piedmontese cattle have a gestation period which is slightly longer than other beef cattle [37], which was also demonstrated in our study by the average gestation length of $292.5 \mathrm{~d}$. Thus, in agreement with the Piedmontese national association, Piedmontese cattle calved hyper mature or oversized newborn calves [39].

The physiological variability of the day of delivery makes it hard to foresee parturition, resulting in the threat of unassisted dystocia. For this reason, different ways to evaluate and anticipate the moment of parturition have been studied for years, including the development of various technologies [9]. Body temperature and IVT decreases have already been described in the scientific literature $[22-25,27,28,40]$. Temperatures measured continuously by data logging thermometers were on average $0.5^{\circ} \mathrm{C}$ lower at parturition than when measured $48 \mathrm{~h}$ before delivery, in both dairy and beef cows $[25,28]$. Furthermore, when sensors were used to evaluate the drop of IVT as the delivery predictor, better accuracy for calving prediction within 24 $h$ before parturition was reported $[9,25,28]$. In beef cows, Aoki and collaborators [25] found that the probability of calving within $36 \mathrm{~h}$ by continuous (every minute) sampling to detect a variation $\geq$ $0.3^{\circ} \mathrm{C}$ in IVT during seven days prepartum was over $83 \%$. In our results, IVT starts to decrease from $60 \mathrm{~h}$ before parturition, but a significant reduction in temperature was seen only $24 \mathrm{~h}$ before parturition.

Intravaginal and body temperatures may vary due to several extrinsic or intrinsic factors (i.e. environmental temperature, degree of physical exercise, and the metabolic state of the animal) $[25,28]$. However, according to Lammoglia et al. [28] during the immediate precalving period (48-8 $\mathrm{h}$ before parturition) $\mathrm{Tb}$ is not influenced by the environmental temperature nor sex of the calf. In our study, physical exercise is minimal before parturition because they are confined in a calving pen. All cows were housed in farms from the same geographical area with similar management and furthermore were in the same metabolic state (just before delivery), therefore, we did not consider these variables in the statistical model used in this study. When season and length of pregnancy effects were evaluated, no effect on the change in intravaginal temperature before parturition was found.

Because a significant diurnal variation in the rectal and vaginal temperature has been reported $[25,28,29]$, in this study the intra- vaginal temperature was measured 2 times per day at 8 a.m. and 8 p.m. Consequently, the diurnal variation in temperature will not influence estimates of the change in temperature that occurs before parturition. Moreover, we indirectly demonstrate this with ROC curves which showed a relatively high Se and Sp.

When we used the ROC curves to calculate the best cut-off for IVT variation as the delivery predictor, a decrease of $0.21^{\circ} \mathrm{C}$ was found to be the change in temperature with the highest Se and Sp. Similarly, Burfeind et al. [28] investigated IVT decreases as a calving predictor in dairy cows using a controlled internal drug release tool modified to operate as a simple thermometer in the vaginal cavity $6 \pm 2 \mathrm{~d}$ prepartum. Burfeind et al. [28] found that a $0.2-0.3^{\circ} \mathrm{C}$ temperature decrease on the day of calving compared to $24 \mathrm{~h}$ before parturition, showed a higher Se (76\%) but a similar $\mathrm{Sp}(79 \%)$ in comparison to our results. Therefore, in this aspect a low accuracy is obtained with a 
decrease of $0.2{ }^{\circ} \mathrm{C}$ of IVT. Consequently, IVT variation may not be the ideal measurement to predict parturition in dairy or beef cattle. Because of the lack of accuracy in the trend of the IVT during the last $24 \mathrm{~h}$ as predictor parameter for parturition, we aimed to use the average IVT itself as a cut-off value to predict parturition within $24 \mathrm{~h}$. The ROC curve for the IVT cut-off within $24 \mathrm{~h}$ prepartum showed that when the average IVT dropped to $38.2^{\circ} \mathrm{C}$ or below, parturition can be predicted with higher AUC and increased Se and Sp in comparison to a change in IVT during the last $24 \mathrm{~h}$ prepartum. It is important to mention that no other studies have considered an average IVT as the cut-off to predict calving; this novel approach appears to be more accurate than checking for a change in IVT.

As previously discussed, dystocia can have a large economic impact on farms due to calf death, veterinary costs, decreased rebreeding efficiency, and injury or death of the cow. Cow-calf Health and Productivity Audit (CHAPA) studies indicate that dystocia is responsible for $33 \%$ of all calf losses and $15.4 \%$ of beef cattle breeding losses. Anderson et al. [41] reported that $57 \%$ and $67 \%$ of calf losses in two studies conducted in Minnesota and Michigan were from dystocia. Our study showed Piedmontese cows have a similar percentage of dystocia (53\%). Interestingly, not all the cows that underwent dystocia showed any calf losses at parturition (due to the prompt assistance). Although the genetic selection in the last decades has worked to improve easier calvings and smaller calf dimension, dystocic parturitions and mainly caesarians are still a problem in the reproductive management of Piedmontese cows; although in a lower percentage than in other double muscle breeds such as Belgian Blue [42]. Nevertheless, a precise and accurate prediction of parturition can improve availability of calving assistance: preventing newborn calf losses and improving future reproductive performance of the cow.

\section{Conclusions}

A simple commercial device to predict calving is a useful tool to improve management of parturition in modern beef farms. In this regard, the average IVT seems to be a better parameter to predict the parturition within $24 \mathrm{~h}$ than the drop in IVT. In farms where the percentage of dystocia is high, an accurate prediction of parturition can significantly improve farmers ability to assist cows at the time of delivery.

\section{References}

[1] Bicalho RC, Galvao KN, Warnick LD, Guard CL. Stillbirth parturition reduces milk production in Holstein cows. Prev Vet Med 2008;84:112e20.

[2] Abdela N, Ahmed WM. Risk factors and economic impact of dystocia in dairy cows: a systematic review. J Reproduction Infertil 2016;7(2):63e74.

[3] Patterson DJ1, Bellows RA, Burfening PJ, Carr JB. Occurrence of neonatal and postnatal mortality in range beef cattle. I. Calf loss incidence from birth to weaning, backward and breech presentations and effects of calf loss on sub- sequent pregnancy rate of dams. Theriogenology 1987;28(5):557e71.

[4] MeyerCL,BergerBJ,KoehlerKJ.Phenotypictrendsinincidenceofstillbirthfor Holsteins in the United States. J Dairy Sci 2001;84:515e23.

[5] Mee JF. Prevalence and risk factors for dystocia in dairy cattle a review. Vet J 2008b;176:93e101.

[6] Lombard JE, Garry FB, Tomlinson SM, Garber LP. Impacts of dystocia on health and survival of dairy calves. J Dairy Sci 2007;90:1751e60.

[7] Hickson RE, Anderson WJ, Kenyon PR, Lopez-Villalobos N, Morris ST. A survey detailing the calving performance of primiparous 2-year-old beef heifers and outcomes of assisted calving. New Zealand Vet J 2002;60:35e41. 
[8] Palombi C, Paolucci M, Stradaioli G, Corubolo M, Pascolo PB, Monaci M. Evaluation of remote monitoring of parturition in dairy cattle as a new tool for calving management. BMC Vet Res 2013;9:191.

[9] Saint-Dizier M, Chastant-Maillard S. Methods and on-farm Devices to predict calving time in cattle. Vet J 2015;205(3):349e56.

[10] Hodge PB, Wood SJ, Newman RD, Shepherd RK. Effect of calving supervision upon calving performance of Hereford heifers. Aust Vet J 1982;58:97e100.

[11] BleulU,SpirigS,Ha€ssigM,K€ahnW.Electrolytesinbovinepre-partum mammary secretions and theirusefulness for predicting parturition. J Dairy Sci 2006;89:3059e65.

[12] StreyID,Sauter-LouisC,BraunertA,LangeD,WeberF,ZerbeH.Establishment of a standard operating procedure for predicting the time of calving in cattle. J Vet Sci 2001;12:177e85.

[13] Dufty JH. Determination of the onset of parturition in Hereford cattle. Aust Vet J 1971;47:77e82.

[14] Matsas DJ, Nebel RL, Pelzer KD. Evaluation of an on-farm blood progesterone test for predicting the day of parturition in cattle. Theriogenology 1992;37: 859e68.

[15] Shah KD, Nakao T, Kubota H, Maeda T. Peripartum changes in plasma estrone sulphate and estradiol-17beta profiles associated with and without the retention of fetal membranes in holstein-friesian cattle. J Reprod Dev 2007;53:279e88.

[16] Wright IA, White IR, Russel AJ, Whyte TK, McBean AJ. Prediction of calving date in beef cows by real-time ultrasonic scanning. Vet Rec 1988;123:228e9.

[17] Maltz E, Antler A. A practical way to detect approaching calving of the dairy cow by a behavior sensor. Precision Livestock Farming. The Netherlands:

Wageningen Academic Publishers; 2007. p. 141 e6.

[18] Saint Dizier M, Chastant-Maillard S. Towards an automated detection of oestrus in dairy cattle. Reprod Domest Anim 2012;47:1056e61.

[19] Rutten CJ, Kamphuis C, Hogeveen H, Huijps K, Nielen M, Steeneveld W. Sensor data on cow activity, rumination, and ear temperature improve prediction of the start of calving in dairy cows.

Computers and Electronics in Agriculture

archive 2017;132:108e18.

[20] Neethirajan S. Recent advances in wearable sensors for animal health management. Sensing and Bio-Sensing Research 2017;12:15e29.

[21] Weisz L. The temperature phenomenon before parturition and its clinical importance. J Am Vet Med Assoc 1943;102:123.

[22] Ewbank R. Predicting the time of parturition in the normal cow. a study of the precalving drop in body temperature in relation to the external signs of imminent calving. Vet Rec 1963;75:367e71.

[23] Graf GC, Petersen WE. Changes in respiration and heart rates, body temperatures, plasma lactic acid levels and plasma creatinine levels caused by stress in daily cattle. J Dairy Sci 1953;36:1036e48.

[24] Porterfield ID, Olson NO. Vaginal temperature of dairy cows before and after calving. J Am Vet Med Assoc 1957;131:381e3.

[25] Aoki M, Kimura K, Suzuki O. Predicting time of parturition from changing vaginal temperature measured by data-logging apparatus in beef cows with twin fetuses. Anim Reprod Sci 2005;86:1e12.

[26] Cooper-Prado MJ, Long NM, Wright EC, Goad CL, Wettemann RP. Relationship of ruminal temperature with parturition and estrus of beef cows. J Anim Sci

2011;89:1020e7. 
[27] Lammoglia MA, Bellows RA, Short RE, Bellows SE, Bighorn EG, Stevenson JS, Randel RD. Body temperature and endocrine interactions before and after

calving in beef cows. J Anim Sci 1997;75:2526e34.

[28] Burfeind O, Suthar VS, Voigtsberger R, Bonk S, Heuwieser W. Validity of prepartum changes in vaginal and rectal temperature to predict calving in dairy cows. J Dairy Sci 2011;94:5053e61.

[29] Vickers LA, Burfeind O, Von Keyserlingk MA, Veira DM, Weary DM, Heuwieser W. Technical note. Comparison of rectal and vaginal temperatures in lactating dairy cows. J Dairy Sci 2010;93:5246e51.

[30] Dufty JH. The influence of various degrees of confinement and supervision on the incidence of dystocia and stillbirths in Hereford heifers. New Zeal Vet J

1981;29:44e8.

[31] Birgel EHJ, Grunert E, Soares JAG. The preliminary stage of labor in cattle in relation to the clinical signs of labor and the course of progesterone secretion for the prediction of the calving time. Deutsce Tiera€rztliche Wochenschrift 1994;101:355e9.

[32] Hanset R, Michaux C, Dessy-Doize C, Burtonboy G. Studies on the 7th rib cut in double muscled and conventional cattle. Anatomical, Histological and Biochemical Aspects Part of the Current Topics in Veterinary Medicine and Animal Science book series (CTVM, vol. 16). 1982.

[33] Arthur PF. Double muscling in cattle a review. Aust. J. Agric. Rs 1995;46: 1493e515.

[34] Silva HM, Wilcox CJ, Thatcher WW, Becker RB, Morse D. Factors affecting days open, gestation length, and calving interval in Florida dairy cattle. J Dairy Sci 1992;75:288e93.

[35] Nogalski Z, Piwczynski D. Association of length of pregnancy with other reproductive traits in dairy cattle Asian-australas. J Anim Sci 2012;25:22e7.

[36] Mee JF. Newborn dairy calf management. Veterinary clinics of North America. Food Animal Practice 2008b;24:1e17.

[37] Ball PJH, Peters AR. Reproduction in cattle. 3a ed. Wiley-Blackwe; 2004.

[39] A.NA.B.O.R.A.P.I. Relazione tecnica. 2016. http://www.anaborapi.it/index.php? option1/4com_content\&view1/4article\&id1/4156:statistiche-

anaborapi\&catid1/426:relazioni-statistiche\&Itemid1/428.

[40] Wrenn TR, Bitman J, Sykes JF. Body temperature variations in dairy cattle during the estrous cycle and pregnancy. J Dairy Sci 1958;41:1071e6.

[41] Anderson P. Minimizing calving difficulty in beef cattle. Extension report. Univesity of Minnesota; 1992. http://www.thebeefsite.com/articles/658/

minimizing-calving-difficulty-in-beef-cattle.

[42] Basset A. Animal welfare approved technical advice fact sheet No. 1: welfare and belgian Blue cattle. 2009. 